\title{
RESISTÊNCIA DE GRÃOS DE MILHO (Zeamays L.) AO FLUXO DE AR
}

\author{
Caroline Nascimento da Silva $^{1}$; Abraão Brito Peixoto ${ }^{2}$ e Laís Maciel Rodrigues ${ }^{3}$ \\ 1. Bolsista PIBIC/CNPq, Graduando em Engenharia de Alimentos, Universidade Estadual de Feira de Santana, e-mail: \\ carolnascimento.fsa@hotmail.com \\ 2. Orientador, Departamento de Tecnologia, Universidade Estadual de Feira de Santana, e-mail: abraaopeixoto@uefs.br \\ 3. Participante do projeto, Departamento de Tecnologia, Universidade Estadual de Feira de Santana, e-mail: \\ lais.engenharia@outlook.com
}

PALAVRAS-CHAVE: Milho; Umidade; Ar.

\section{INTRODUÇÃO}

No armazenamento eficiente de grãos agrícolas a granel, é mandatório o controle de aeração após a operação de secagem. Com vistas à longevidade do armazenamento e manutenção da qualidade dos grãos, a aeração pós secagem reduz a atividade biológica da biota nativa e evita a deterioração do produto estocado. Durante essa operação, um fluxo de ar forçado permeia a massa de grãos e escoa em canais intergranulares, o que causa resistência ao fluxo concomitantemente à perda de carga, também conhecida como perda de pressão ou pressão estática a ser vencida. Tal resistência ao fluxo de ar em leitos fluidizados depende de diversos fatores, tais como: velocidade superficial, profundidade do leito de grãos, presença de impurezas no produto, tamanho, forma, umidade, porosidade e rugosidade do produto. $\mathrm{O}$ preenchimento da coluna de grãos pode seguir uma metodologia interferente na sua compactação, direção do fluxo de ar e resistência do produto à passagem de um fluxo de ar. $\mathrm{Na}$ construção dos sistemas, as chapas perfuradas, os dutos perfurados e as tubulações, são responsáveis por um aumento da queda de pressão (CALDERWOOD, 1973; HAQUE et al., 1978; JAYAS, 1987; BROOKER et al., 1992). Nos cálculos da resistência causada pela massa de grãos ao fluxo de ar, os principais parâmetros envolvidos são a porosidade e as massas especificas real e aparente, diretamente influenciadas pela presença de impurezas no produto e seu teor de umidade. Segundo Mohsenin (1978), a porosidade de uma massa granular pode ser definida como sendo a quantidade de espaços vazios ocupados pelo ar nos espaços intergranulares, podendo variar de 30 a 50\%. Couto et al. (1999), estudando a porosidade de amostras com frutos de café (variedades catuaí e timor) contendo o produto verde e cereja, verificaram que a porosidade variou de 38,8 a 53,0\%, valores estes que se encontram na mesma faixa da maioria dos grãos agrícolas. Chandasekar\&Viswanathan (1999), estudando propriedades físicas de café descascado das espécies arábica e robusta, concluíram que os valores de porosidade diminuíram com o aumento do teor de água na faixa de 9,9 a 30,6\% b.u. Hall et al. (1972) investigaram, durante a secagem, o efeito da redução do teor de umidade de grãos de milho nos valores da massa específica real e porosidade.

Dado o exposto e tendo em vista o potencial produtivo de cultivares agrícolas, tanto em âmbito nacional como estadual, torna-se valioso identificar propriedades fluidodinâmicas de grãos de milho com vistas ao melhoramento da qualidade deste cultivar durante a secagem e o armazenamento, já que, a depender da região em que o cultivo acontece, as características de armazenamento e secagem devem se adequar às sazonalidades climáticas típicas de cada região.

Neste âmbito, percebe-se escassez de estudos com ênfase neste setor, quando direcionado a uma tipificação regional. Desse modo, os mecanismos adotados para as operações com grãos de milho em uma dada região podem estar sendo utilizados com base em dados gerados para 
o mesmo produto, mas cultivado em outra região. Isso pode impactar em gastos energéticos, o que onera o custo de produção e inflaciona o preço destinado ao consumidor final.

\section{MATERIAL E MÉTODOS OU METODOLOGIA}

O trabalho foi desenvolvido no Laboratório de Panificação e no Laboratório de Embalagens da Universidade Estadual de Feira de Santana. A metodologia para realização do projeto dividiu-se em três etapas: 1- umidificação dos grãos de milho; 2- medição da umidade por balança infra-vermelho; 3 - medição da umidade por método de estufa.

\section{$1^{\text {a }}$ etapa - Umidificação dos grãos de milho}

Os grãos de milho foram submetidos ao vapor de água em tempos diferentes, sem contato direto com a água. A água foi mantida sob temperatura constante para todas as amostras.

\section{$2^{a}$ etapa- Análise de Umidade por Balança Infra-vermelho}

Determinou-se a umidade por balança de infravermelho (Infrared Moisture Balance), previamente calibrada, com temperatura ajustada a $90^{\circ} \mathrm{C}$ e com tempo de estabilização de $60 \mathrm{~s}$ (INSTITUTO ADOLFO LUTZ, 2005).

\section{$3^{\text {a }}$ etapa- Análise de Umidade por método de Estufa}

As vidrarias foram calibradas através do aquecimento a $105 \pm 3^{\circ} \mathrm{C}$ por 1 hora, e resfriadas em dessecador por 30 minutos. Após a calibragem, os grãos de milho foram transferidas para as vidrarias, pesados e permaneceram na estufa por um período 24 horas sob temperatura de $105 \pm 3^{\circ} \mathrm{C}$ (BRASIL, 1992). Posteriormente, foram resfriadas em dessecador por 30 minutos. Ao fim do procedimento, as sementes foram novamente pesadas, utilizando uma balança previamente calibrada de precisão de $0,0001 \mathrm{~g}$.

\section{RESULTADOS}

Os grãos de milho foram submetidos ao vapor por 18, 22, 24 e 26 minutos. Na análise de umidade por infra-vermelho, os valores obtidos estão apresentados na tabela 1.

Tabela 1. Valores de umidade obtidos por infra-vermelho

\begin{tabular}{c|c}
\hline $\begin{array}{c}\text { Tempo exposto ao } \\
\text { vapor (minutos) }\end{array}$ & $\begin{array}{c}\text { Umidade } \\
(\%)\end{array}$ \\
\hline 18 & 9,96 \\
22 & 10,95 \\
24 & 16,12 \\
26 & 17,38 \\
\hline
\end{tabular}

Para análise em estufa, em triplicata, obteve-se os valores apresentados na tabela 2.

Tabela 2. Valores de umidade obtidos por método de estufa

\begin{tabular}{c|c}
\hline $\begin{array}{c}\text { Tempo exposto ao } \\
\text { vapor (minutos) }\end{array}$ & $\begin{array}{c}\text { Umidade } \\
(\%)\end{array}$ \\
\hline 18 & 12,65 \\
22 & 12,86 \\
24 & 15,02 \\
26 & 16,22 \\
\hline
\end{tabular}

\section{CONSIDERAÇÕES FINAIS}


A partir dos resultados obtidos, observa-se a diferença de umidade na determinação por dois métodos distintos. A análise de resistência ao fluxo de ar foi impossibilitada de ser realizada pelas dificuldades encontradas, o curto período de tempo disponível e pela falta de equipamentos.

\section{REFERENCIAS}

AFONSO, A. D. L. Gradiente de pressão estática em camadas de fruto de café (Coffea arábica L.) com diferentes teores de umidade.Viçosa: UFV, 1994. 68p. Dissertação Mestrado AFONSO JÚNIOR, P. C. Aspectos físicos, fisiológicos e de qualidadedo café em função da secagem e do armazenamento. Viçosa:UFV, 2001. 384p. Tese Doutorado

ANDRADE, E. T.; COUTO, A. M.; QUEIROZ, D. M.; PEIXOTO, A. B. Determinação de propriedades térmicas de grãos de milho. Ciência e Agrotecnologia, Lavras, v. 28, n. 3, p. 488-498, 2004.

BRASIL. Ministério da Agricultura e Reforma Agrária. Regras para análise de sementes. Brasília, DF, 1992. 365 p.

BROOKER, D. B.; Bakker-Arkema, F. W.; Haal, C. W. Drying andstorage of grains and oilseeds. New York: AVI. 1992. 450p.

BRUSEWITZ, G. H. Density of rewetted high moisture grains. Transactionsof the ASAE, St. Joseph, v.18, n.5, p.935-938, 1975.

CALDERWOOD, D. L. Resistance to airflow of rough, brown and milledrice. Transactions of the ASAE, St. Joseph, v.16, n.3,p.525-527, 532, 1973.

CHANDRASEKAR, V.; VISWANATHAN, R. Physical and thermal propertiesof coffee. Journal of Agricultural Engineering, n.73,p.227-234, 1999.

COUTO, S. M.; MAGALHÃES, A. C.; QUEIROZ, D. M.; BASTOS, I. T.Massa específica aparente e real e porosidade de grãos decafé em função do teor de umidade. Revista Brasileira deEngenharia Agrícola e Ambiental, Campina Grande, v.3,n.1, p.61-68, 1999.

HALL, G. E. Test-weight changes of shelled corn during drying.Transactions of the ASAE, St. Joseph, v.15, n.2, p.320-323,1972.

HAQUE, E.; AHMED, Y. N.; DOYOE, C. W. Static pressure drop infixed beds of grain as affected by grain moisture content.Transactions of the ASAE, St. Joseph, v.25, n.4, p.1095$1098,1982$.

HAQUE, E.; FOSTER, G. H.; CHUNG, D. S. Static pressure drop acrossa bed of corn mixed with fines. Transactions of the ASAE, St.Joseph, v.21, n.5, p.997-1000, 1978.

JAYAS, D. S. Resistance of bulk canola oilseed to airflow.Saskatoon: University of Saskatchewan, 1987, 203p.Doctoral Thesis

MOHSENIN, N. N. Physical properties of plant and animal materials.2.ed. New York: Gordon and Breach Science Publishers, 1978. 742p.

MOREIRA, S. M. C.; CHAVES, M. A.; OLIVEIRA, L. M. Comparação daeficiência de líquidos na determinação da massa específica aparentede grãos agrícolas. Revista Brasileira de Armazenamento,Viçosa-MG, v.9/10, n.1/2, p.22-24, 1985.

SHEDD, C. K. Some new data on resistance of grains to air flow.Journal of Agricultural Engineering, v.32 n.9, p.493-495.1951.

SINHA, R. N. Interrelations of physical, chemical and biologicalvariables in the deterioration of stored grains. In: Sinha, R. N.;Muir, W. E. (ed.). Grain storage: part of system. Westport,1973. p.15-47. 